\title{
Impacto econômico da construção sustentável: a reforma do Estádio do Mineirão
}

Economic impact of sustainable construction: the renovation of the Mineirão Stadium

Jairo Cardoso de Oliveira[a] (D) , Ana Cristina de Faria ${ }^{[b]}$

[a] Universidade Nove de Julho (UNINOVE), São Paulo, SP, Brasil

[b] Universidade de São Paulo (USP), Faculdade de Economia, Administração e Contabilidade (FEA), Laboratório de Gestão Estratégica de Custos (CMS-Lab), São Paulo, SP, Brasil

Como citar: Oliveira, J. C., \& Faria, A. C. (2019). Impacto econômico da construção sustentável: a reforma do Estádio do Mineirão. urbe. Revista Brasileira de Gestão Urbana, 11, e20180031. https://doi.org/10.1590/2175-3369.011.001.A006

\section{Resumo}

O objetivo deste artigo é mensurar o impacto econômico da adoção do conceito de construção sustentável no projeto do Estádio do Mineirão. 0 método empregado nesta pesquisa de natureza qualitativa e com abordagem exploratória é o da pesquisa documental ex-post-facto, já que os dados secundários foram obtidos por meio de informações publicadas em períodos anteriores ao que a pesquisa foi desenvolvida. Para atingir ao objetivo do trabalho, os valores investidos para tornar a construção sustentável foram obtidos mediante pesquisa documental no website do Estádio do Mineirão e de fontes, tais como: Tribunal de Contas da União (TCU), Banco Nacional de Desenvolvimento Econômico e Social (BNDES) e imprensa, ainda avaliados em três cenários. Quanto aos ganhos que a construção sustentável oferece, avaliou-se a eficiência na utilização de energia elétrica e na reutilização de água, sendo essas duas rubricas responsáveis por, aproximadamente, $\mathrm{R} \$ 2$ milhões anuais em economias. Constatou-se que a consciência sustentável na construção do Estádio do Mineirão foi atingida por sua obrigatoriedade para a obtenção de financiamento no BNDES, comprovada pela obtenção da certificação Leadership in Energy and Environmental Design (LEED) Platinum.

Palavras-chave: Sustentabilidade. Eficiência energética. Certificação LEED.

\section{Abstract}

This article aims to measure the economic impact of adopting a sustainable construction concept in the Mineirão Stadium project. We adopted the ex-post-fact Documentary Research in this qualitative research, since the secondary data were obtained from published information in periods prior to this research. In order to achieve the project goal, we obtained the amounts invested to make the construction sustainable through documental research in the Mineirão Stadium website, and sources such as Tribunal de Contas da União (TCU), Banco Nacional de Desenvolvimento Econômico e Social (BNDES), and press. The amounts were also evaluated in three distinct scenarios. We evaluated the gains that sustainable construction offers through the efficiency in the use of electricity and the re-use of water. These two items being responsible

JCO é doutorando em Administração e mestre em Gestão de Projetos, e-mail: jairo.oliveira13@gmail.com

ACF é doutora e mestra em Controladoria e Contabilidade, e-mail: anacfaria@uol.com.br 
for saving approximately two million Brazilian Reais (BRL) per year. We verified that the sustainable awareness in the construction of the Mineirão Stadium was reached due to its obligation to obtain financing from the National Bank for Economic and Social Development (BNDES), proven by the Leadership in Energy and Environmental Design - LEED Platinum certification.

Keywords: Sustainability. Energy efficiency. Certification LEED.

\section{Introdução}

0 tema sustentabilidade vem sendo discutido e estudado por meio de abordagens ambientais, sociais, econômicas de forma mais intensa nos últimos anos. Um dos temas de estudo diz respeito ao processo de urbanização, em que a mudança de ocupação de espaço e de tipo de habitação, aliada às altas taxas de consumo de recursos naturais, ocorridas principalmente em países em desenvolvimento, incrementa a poluição urbana e impacta as condições ambientais, com efeitos na redução da camada de ozônio, no aumento do efeito estufa e na redução da biodiversidade (Malheiros et al., 2013).

No contexto da urbanização, a indústria da construção civil tem um papel relevante (Silva et al., 2003), muito embora a sustentabilidade nessa área ainda se encontre em estágio inicial de desenvolvimento (Silva \& Pardini, 2010). As chamadas construções sustentáveis (tradução do termo inglês Green Buildings) buscam incrementar eficiência do uso de recursos, eficiência energética, conservação das áreas naturais e da biodiversidade, harmonização ambiental, prevenção da poluição etc. (Medeiros et al., 2012).

A construção sustentável contempla conceitos de desenvolvimento sustentável no segmento da construção civil, a partir do momento em que é implementada por gestores comprometidos com os princípios ambiental, social e econômico (Bonilla et al., 2012). A construção civil também necessita que as operações sejam sustentáveis, e tais ações devem ser consideradas desde os investimentos realizados. Gavronski (2009, p. 73) considera que uma operação sustentável é "[...] aquela que é eficiente economicamente, enquanto responsável ambiental e socialmente".

O Brasil recebeu dois dos maiores eventos esportivos mundiais (Copa do Mundo de Futebol em 2014 e Jogos Olímpicos em 2016), com praças esportivas construídas ou adaptadas para abrigar esses eventos. o Banco Nacional de Desenvolvimento Econômico e Social (BNDES) atuou como agente financiador desses projetos de construção ou adaptação, mas vinculou a disponibilização dos recursos à obrigatoriedade de a construção apresentar critérios sustentáveis que deveriam ser comprovados por meio de uma certificação de reconhecimento internacional.

Diante desse contexto, este trabalho busca responder à seguinte questão de pesquisa: qual é o impacto econômico da implantação de práticas sustentáveis para obtenção de certificação reconhecida na construção, operação e manutenção de praça esportiva? Para responder a essa questão, o objetivo deste artigo foi mensurar o impacto econômico da adoção do conceito de construção sustentável no projeto do Estádio do Mineirão, em Minas Gerais.

Esse estádio foi escolhido pelo fato de ter sido o único entre todos os outros estádios construídos ou reformados para o evento Copa do Mundo 2016 a obter a certificação Leadership in Energy and Environmental Design (LEED) Platinum, o mais alto nível de certificação concedido por essa organização.

0 Estádio do Mineirão também utilizou o modelo de parceria público-privada (PPP), pela qual o Estado de Minas Gerais concedeu o uso do estádio por um período de 25 anos à iniciativa privada em troca da reforma e da adequação aos padrões estabelecidos pela FIFA (Fédération Internationale de Football Association).

\section{Sustentabilidade}

Antes considerados apenas uma preocupação de ativistas ambientais e organizações não governamentais, as alterações climáticas e do ambiente, o excesso de poluição nos grandes centros, a 
redução das fontes de água potável, entre outros pontos, trouxeram o tema sustentabilidade para a discussão com a sociedade. Na área acadêmica, o tema vem sendo cada vez mais estudado por pesquisadores preocupados em tratá-lo de forma adequada e entender todas as dimensões a serem contempladas (econômica, social e ambiental).

Em pesquisa bibliométrica, Souza \& Ribeiro (2013) verificaram que, no período de 1992 a 2011, entre 20 periódicos brasileiros classificados no Qualis CAPES entre A2 e B2, foram publicados 396 artigos sobre o tema sustentabilidade. Os autores apontam que, de 1992 a 1995, houve um destaque na elaboração de trabalhos a respeito do tema, como consequência das discussões da Conferência Rio-92.

Nos anos seguintes, ocorreu uma queda nas publicações, que voltaram a despontar a partir de 2002. Souza \& Ribeiro (2013) concluem que a área ainda não havia atingido a maturidade nas publicações, mas que, devido à tendência de incremento do número de artigos publicados, estava no caminho de consolidar-se. Conhecer os contornos do tema sustentabilidade é uma necessidade que, cada vez mais, será exigida no ambiente acadêmico, tal como no empresarial e social, e demandará novas competências dos profissionais envolvidos nessa área (Martins et al., 2014).

No ambiente empresarial, a sustentabilidade evolui de ações com cunho apenas filantrópico para ser considerada nas discussões estratégicas como uma forma de garantir a sobrevivência das empresas (Nidumolu et al., 2009). As tragédias ambientais ocorridas foram talvez a forma mais dura para que opinião pública se conscientizasse sobre as consequências das agressões ao meio ambiente (Van Bellen, 2004) e exigisse punições para as empresas causadoras, marcando, de forma indelével, suas marcas para sempre. Um segmento que causa muitos impactos no meio ambiente é a construção civil, que merece ser estudada.

\section{Construções sustentáveis}

A construção civil, em especial a construção, a operação e a demolição de edifícios, configura-se como uma das atividades humanas que causam grande impacto no meio ambiente (Silva et al., 2003). Essa é uma das razões pelas quais a legislação internacional e, especificamente, a brasileira exigem a apresentação de estudos de avaliação ambiental (Lei no 6.938 de 1981, Constituição Federal, artigo 225, parágrafo 1ํㅡ, inciso IV, Resoluções no 1 e no 237 do CONAMA, entre outras) e definem a apresentação de estudos e de relatórios que avaliam os impactos no meio ambiente para que construções possam ser licenciadas (Barbieri, 1995).

Essa indústria está em processo de adaptação aos novos tempos, uma vez que não são mais aceitáveis projetos que não considerem a sustentabilidade como fator a ser avaliado em sua fase de definição inicial (Gareis et al., 2013). A iniciação de um projeto, em especial os de novas construções, deve considerar um quadro de obrigações sustentáveis, de forma a atender não somente aos objetivos de curto prazo, mas também aos conceitos de geração de valor, econômico, ecológico, orientação social, médio/longo prazo, bem como considerar as orientações quanto ao desenvolvimento local, regional e global (Gareis, 2013).

Nesse contexto, é importante precaver-se daquilo que o mercado já intitulou como "esverdeamento" (greeness ou green washing) de produtos e soluções, ou seja, uma prática que não colabora para o desenvolvimento sustentável e visa apenas tentar se aproveitar de boa consideração por parte de consumidores (Walker \& Wan, 2012). Uma das formas de evidenciar a adoção de práticas sustentáveis na construção civil e distingui-las do "esverdeamento" é o processo de certificação de construções sustentáveis (Medeiros et al., 2012).

Sistemas de certificações de construções sustentáveis são comuns em países europeus, assim como nos Estados Unidos, no Japão, no Canadá, na Austrália e em Hong Kong (Azhar, et al., 2011; Bueno \& Rossignolo, 2010; Dalla Costa \& Moraes, 2013; Candace Say, 2008; Silva et al., 2003; Zangalli, 2013).

A Tabela 1 apresenta as quantidades de aplicações e certificações para os sistemas que disponibilizam essas informações em seus websites. No caso do sistema LEED, a informação quanto ao número de 
aplicações e de certificações referentes a empreendimentos no Brasil apresenta divergência entre o website americano e o brasileiro da mesma instituição, razão pela qual são apresentadas as duas versões.

Tabela 1 - Certificações em construções sustentáveis

\begin{tabular}{cccccc}
\hline Sistema & Origem & $\begin{array}{c}\text { Número de } \\
\text { aplicações }\end{array}$ & $\begin{array}{c}\text { Número de } \\
\text { certificações }\end{array}$ & $\begin{array}{c}\text { Aplicações } \\
\text { no Brasil }\end{array}$ & $\begin{array}{c}\text { Certificações no } \\
\text { Brasil }\end{array}$ \\
\hline BREEAM & Reino Unido & 2.260 .390 & 557.559 & 3 & 2 \\
HQE & França & & 380.000 & & 339 \\
LEED & EUA & 104.148 & 55.043 & 708 & 400 \\
LEED BRASIL & EUA & & & 1.226 & \\
NABERS & Austrália & & 4.504 & & \\
Green Globes & EUA & & 1.418 & \\
DGNB & Alemanha & 1.279 & 711 & & 11 \\
CASBEE & Japão & & 541 & \\
HK BEAM & Hong Kong & 917 & 534 & \\
AQUA & Brasil & & & \\
\hline
\end{tabular}

Fonte: elaborada pelos autores a partir dos websites das organizações em consulta realizada em 27 de abril de 2017.

A certificação LEED (utilizada nos estádios brasileiros da Copa do Mundo 2014) estabelece um padrão de métricas e de normas e, por meio de um projeto integrativo, estimula a competição para tornar as construções mais sustentáveis. A certificação diferencia entre novas construções, interiores, edificações existentes, residências e bairros (US Green Building Council - USGBC, 2013).

As certificações são atribuídas conforme a quantidade de pontos que são obtidos em cada uma das nove categorias avaliadas (Processo Integrativo, Localização e Transporte, Terrenos Sustentáveis, Eficiência Hídrica, Energia e Atmosfera, Materiais e Recursos, Qualidade do Ambiente Interno, Inovação, Processos e Prioridade Regional) (GBC Brasil, 2017). A quantidade de pontos para cada nível de certificação pode ser verificada na Tabela 2.

Tabela 2 - Níveis de certificação LEED

\begin{tabular}{cc}
\hline Certificação & Número de pontos \\
\hline Certified & 40 a 49 \\
Silver & 50 a 59 \\
Gold & 60 a 79 \\
Platinum & Mais de 80 \\
\hline
\end{tabular}

Fonte: GBC Brasil (2017).

É normal acreditar que a implantação de práticas sustentáveis possa encarecer o produto ou o serviço final. Entretanto, conforme Nidumolu et al. (2009), essas práticas não se configuram como custos que prejudicam a obtenção de lucro; pelo contrário, atuam na sua maximização. De acordo com esses autores, a utilização de equipamentos mais novos, já adaptados para consumir menos energia ou combustível, por exemplo, preservam recursos materiais e ambientais e, ainda em médio prazo, trazem retorno econômico-financeiro.

No caso de construções sustentáveis, os aspectos ambiental e econômico, tais como custos crescentes de energia elétrica, são responsáveis pela demanda desse tipo de construção (Azhar et al., 2011). Conflitos, como a adoção ou não de princípios de construções sustentáveis, podem ocorrer entre as partes interessadas na construção civil. Incorporadores, corretores e vendedores consideram a adoção de 
práticas sustentáveis um argumento de venda. Proprietários e gerenciadores consideram a possibilidade de redução de custos com operação e manutenção dos empreendimentos.

\section{Impactos econômicos em construções sustentáveis}

De acordo com Lützkendorf \& Lorenz (2005), em geral, a indústria da construção civil não considera aspectos sustentáveis, buscando o retorno econômico imediato. No entanto, acrescentam que essa posição tem sido questionada e que o ciclo de custo total, que engloba o custo da aquisição e propriedade (incluindo operação, manutenção e renovação) da construção, está recebendo maior atenção.

Contribuindo com essa tendência, von Paumgartten (2003) apresenta o caso de uma construção em Milwaukee (EUA), em que técnicas de iluminação natural, reutilização de água, utilização de água da chuva, sistemas de controles inteligentes de equipamentos elétricos e mecânicos obtiveram uma redução de até $31 \%$ no consumo de energia elétrica.

Esse autor cita uma estimativa da American Society of Heating, Refrigerating and Air-Conditioning Engineers (ASHRAE), em que a diferença no ciclo de custo total, considerando um período de 40 anos, pode atingir $25 \%$ de redução, quando se compara um edifício que foi construído com alto desempenho de ações sustentáveis a outro que não tenha sido concebido dessa forma.

Em outra pesquisa realizada nos Estados Unidos envolvendo 33 empreendimentos verdes, cuja construção foi finalizada ao longo dos anos de 1995 a 2004, foi verificado um incremento de custo médio de $2 \%$ para construções que obtiveram certificações LEED Gold e Silver e cerca de 6,5\% para a construção que obteve a certificação máxima Platinum (Kats, 2003).

No entanto, o mesmo estudo revela que os custos com redução de consumo de energia elétrica se situam, na média, em 36\%, quando comparado com edificações convencionais. Conforme Kats et al. (2003), os custos adicionais com elementos sustentáveis configuram um acréscimo de $2 \%$ ao total da construção, totalmente compensados pelo resultado de $20 \%$ de economias, quando considerado todo um ciclo de vida da construção de pelo menos 20 anos.

Em uma pesquisa mais recente e com uma amostra de 160 empreendimentos com certificação LEED, Nyikos et al. (2012) apontaram que construções certificadas apresentaram uma redução de custo operacional de, aproximadamente, US\$ 7 por metro quadrado, quando comparadas às construções não certificadas. Ainda nesse estudo, os autores apontaram que, nas mesmas condições, os custos com energia elétrica foram 31\% menores, ou seja, muito similar ao levantamento feito pela ASHRAE. Entretanto, diferentemente da avaliação feita por Kats et al. (2003), os autores apuraram que os custos para atingir a certificação LEED estavam compreendidos entre o intervalo de 2,5 a 9,4\% do custo da construção, com uma média de $4,1 \%$.

No ambiente brasileiro, os estudos empreendidos analisam, em sua maioria, o desempenho de empresas que fazem parte do Índice de Sustentabilidade Empresarial (ISE) da BM\&FBovespa (atual B3) com outras empresas. Em um desses estudos sobre rentabilidade e risco realizado com 34 empresas com ações listadas no ISE e 117 elegíveis ao ISE, mas não efetivamente listadas nesse índice, foi verificado que não existem diferenças significativas entre esses dois grupos (Nunes et al., 2012). Os autores sugerem que os custos com a sustentabilidade são compensados por ganhos ou ainda que a magnitude deles não chega a afetar os resultados econômicos.

\section{Metodologia de pesquisa}

Esta pesquisa foi desenvolvida no $2^{\circ}$ semestre de 2016 e teve como objeto de estudo o Estádio Governador Magalhães Pinto, o Mineirão, em Minas Gerais. Esse estádio foi uma das sedes da Copa do Mundo de Futebol 2014 e também sediou partidas de futebol dos Jogos Olímpicos Rio 2016. 
A pesquisa de natureza qualitativa, com abordagem exploratória, é uma pesquisa documental ex-post-facto, já que os dados secundários foram obtidos por meio de relatórios publicados em períodos anteriores ao que esta pesquisa foi desenvolvida. Uma pesquisa documental, na visão de Gil (2010), contempla a análise de documentos, como materiais desenvolvidos com objetivo de divulgação, entrevistas, além de legislação vigente, informações que constam em endereços eletrônicos de internet etc.

Esse tipo de pesquisa evidencia algumas vantagens, pois "[...] os documentos constituem rica fonte de dados; como suscitam ao longo do tempo, torna-se a mais importante fonte de dados em qualquer pesquisa de natureza histórica e; não exige contato com o sujeito da pesquisa [...]" (Gil, 2010, p. 52). Já que os gestores da PPP e os atuais gestores do estádio não quiseram conceder entrevistas ou fornecer relatórios aos pesquisadores, a pesquisa documental foi a alternativa plausível para o desenvolvimento do trabalho.

No que tange à coleta de dados, foram avaliados, por meio de pesquisa documental, dados secundários de fontes públicas, incluindo relatórios disponibilizados no portal da transparência e órgãos, tais como: BNDES, relatórios e atas do Tribunal de Contas da União (TCU), entrevistas de representantes do consórcio Minas Arena concedidas a veículos de comunicação, entre outros documentos. Esses dados foram obtidos nos websites dos órgãos e em buscas por palavras-chave em sites de busca.

As análises dos dados coletados foram feitas com o foco principal de determinar os valores de gastos relacionados aos itens relacionados à construção sustentável, principalmente em medidas de economia de energia elétrica e de reutilização de água, bem como na indicação dos benefícios obtidos com estes.

$\mathrm{Na}$ avaliação das entrevistas dos representantes do consórcio Minas Arena, a principal atenção foi dada aos valores indicados, destacando quais deles podem ser relacionados às construções sustentáveis e quais benefícios foram obtidos. Os benefícios foram transformados em valores econômico-financeiros para permitir o cálculo de valor presente e da determinação da viabilidade econômica da construção sustentável.

O Estádio do Mineirão, objeto de estudo, é representativo do modelo de construções e reformas que adotaram princípios sustentáveis em sua concepção. Possui como característica ímpar o fato de ter sido definido como uma parceria público-privada (PPP), em que a empresa responsável pela construção também é a responsável pela operação do estádio por um longo período, com interesse em obter retorno econômico dentro desse período. Todos os estádios e as arenas utilizados na Copa do Mundo buscaram a certificação LEED, sendo que dez deles obtiveram as certificações, conforme a Tabela 3.

Tabela 3 - Aplicações e certificações LEED das arenas da Copa do Mundo de 2014

\begin{tabular}{|c|c|c|c|c|c|c|}
\hline Arena & Estado & Certificado & $\begin{array}{c}\text { Nível da } \\
\text { certificação }\end{array}$ & $\begin{array}{l}\text { Qtde } \\
\text { pontos }\end{array}$ & $\begin{array}{c}\text { Data de } \\
\text { aplicação }\end{array}$ & $\begin{array}{l}\text { Data da } \\
\text { certificação }\end{array}$ \\
\hline Arena da Amazônia & AM & Sim & Certified & 41 & 13/10/2009 & $12 / 06 / 2014$ \\
\hline Estádio Nacional de Brasilia & DF & Não & & & $15 / 02 / 2009$ & \\
\hline Mineirão 2014 & MG & Sim & Platinum & 81 & $17 / 12 / 2009$ & $27 / 06 / 2014$ \\
\hline Arena Multiuso de Cuiabá & MT & Não & & & $13 / 05 / 2010$ & \\
\hline Arena Fonte Nova & BA & Sim & Silver & 53 & $25 / 10 / 2010$ & $10 / 02 / 2014$ \\
\hline Arena das Dunas & $\mathrm{RN}$ & Sim & Certified & 48 & $07 / 06 / 2011$ & $09 / 01 / 2015$ \\
\hline Maracanã & RJ & Sim & Silver & 58 & $12 / 05 / 2011$ & $11 / 06 / 2014$ \\
\hline Arena Multiuso de Pernambuco & PE & Sim & Silver & 59 & 20/10/2011 & $10 / 06 / 2014$ \\
\hline Estádio Atlético Paranaense & PR & Sim & Silver & & $06 / 12 / 2011$ & $22 / 11 / 2017$ \\
\hline Estádio Beira Rio & RS & Sim & Silver & 50 & $14 / 08 / 2012$ & $01 / 08 / 2014$ \\
\hline Arena Corinthians - Itaquerão & SP & Sim & Certified & 45 & $30 / 12 / 2012$ & $21 / 06 / 2017$ \\
\hline Consórcio Castelão & CE & Sim & Certified & 46 & $18 / 06 / 2013$ & $28 / 11 / 2013$ \\
\hline
\end{tabular}

Fonte: GBC Brasil (2017). 
O foco concentra-se na construção sustentável da arena do Mineirão por meio de parceria públicoprivada (PPP), envolvendo o governo do Estado de Minas Gerais e um consórcio de construtoras, que obteve a certificação LEED Platinum para construções sustentáveis. A relevância dessa certificação obtida pela arena (foi a segunda em todo o mundo, considerada na categoria de arenas esportivas), bem como a quantidade de pontos muito maior que as demais, demonstra que o projeto dessa arena esteve à frente de todas as demais na utilização de conceitos de construção sustentável (Brasil, 2014).

\section{Descrição e análise dos resultados}

O modelo de contratação utilizado no Estádio objeto deste estudo foi a parceria público-privada (PPP) entre o governo de Minas Gerais, aberto como licitação pública, no modelo de "menor valor da remuneração a ser paga pelo poder concedente" (Minas Gerais, 2010a). Nesse modelo, o proponente se encarrega das obras de adequação, incluindo obtenção de financiamento, com a consequente operação e manutenção do estádio por um período de 25 anos.

Durante esse período, o governo de Minas Gerais executou um pagamento mensal ao proponente, que levou em consideração as receitas dele com comercialização de espaços publicitários, estacionamento e outros empreendimentos do escopo do proponente ou eventos, que são abatidos desse pagamento mensal (Minas Gerais, 2012).

A Minas Arena - Gestão de Instalações Esportivas S.A., uma sociedade de propósito específico (SPE), formada pelas empresas Construcap CCPS Engenharia e Comércio S.A., Egesa Engenharia S.A. e Hap Engenharia Ltda., apresentou, em 10 de agosto de 2010, proposta de menor remuneração no valor de R\$ 3,7 milhões, sendo declarada vencedora do pleito.

O contrato entre o consórcio e o governo de Minas Gerais foi assinado em 21 de dezembro de 2010. De acordo com o referido contrato, o consórcio tem por obrigação executar os serviços de adequação do estádio em dois anos e, depois desse prazo, exercer a atividade de gerir o estádio por um período de 25 anos, podendo ser prorrogado por mais 10 anos (Minas Gerais, 2010b).

As construções necessárias para esses eventos contaram com financiamento do BNDES. Para as arenas que sediaram jogos da Copa do Mundo, o BNDES, por meio do "Programa BNDES de Arenas para a Copa do Mundo de 2014 - BNDES ProCopa Arenas", ofereceu empréstimo no valor de até R\$ 400 milhões e condicionou a contratação com a apresentação, dentre outras, de "estudo de viabilidade econômica da arena, com foco na Sustentabilidade financeira e na solução de gestão" (BNDES, 2014).

A limitação de valor do financiamento foi definida pela Resolução no 3.801/2009 do Conselho Monetário Nacional (Brasil, 2009). Após a contratação, o BNDES exigia a “[...] certificação emitida para o empreendimento por entidade certificadora de Qualidade Ambiental reconhecida internacionalmente e/ou acreditada pelo INMETRO, em até 12 meses após o término do prazo de utilização dos recursos [...]" (BNDES, 2014).

Para que sejam implementados conceitos de construção sustentável em um empreendimento, tal como exigido pelo BNDES, é realizada análise da viabilidade econômica do projeto, no intuito de dar suporte à tomada de decisão para implementação de todos os requisitos de políticas ambientais para obter a certificação alcançada.

Item fundamental para determinar o resultado econômico do investimento na construção sustentável do estádio pesquisado, a determinação do valor desse investimento não é informação disponível em fontes secundárias. A proposta vencedora não detalhou a formação de seus custos, informando apenas a menor remuneração a ser paga pelo governo.

A informação sobre custos decompostos foi obtida por meio de informação divulgada pelo Tribunal de Contas da União, no Relatório de Acompanhamento TC 015.236/2011-0 (TCU, 2012), dando conta de que os usos e as fontes para esse estádio foram apresentados de acordo com a Tabela 4.

Os custos foram atualizados, conforme comprova o Relatório de Acompanhamento TC 028.249/20135 (TCU, 2014), e apontam que o valor total das obras alcançou o montante de $\mathrm{R} \$ 647.931 .000,00$. A 
considerar os valores apontados pelo TCU, os custos com "investimento socioambiental" atingiriam o valor de $\mathrm{R} \$ 2.749 .000,00$, correspondendo ao percentual de $0,42 \%$ do total do investimento (e não $0,5 \%$ como aparece na Tabela 4).

Tabela 4 - Resumo de usos e fontes

\begin{tabular}{|c|c|c|c|c|c|}
\hline $\begin{array}{l}\text { Total dos usos } \\
\text { Projeto Arena Mineirão }\end{array}$ & $\begin{array}{r}\text { Realizado até } \\
2010\end{array}$ & 2011 & 2012 & Total & $\%$ \\
\hline 1 FIN EM & 6.000 & 336.798 & 202.688 & 545.486 & $93,1 \%$ \\
\hline 1.1 Estudos e projetos & & 28.481 & 500 & 28.981 & $4,9 \%$ \\
\hline 1.2 Obras civis & & 242.010 & 105.335 & 347.345 & $59,3 \%$ \\
\hline 1.3 Montagens e instalações & & 63.070 & 80.271 & 143.342 & $24,5 \%$ \\
\hline 1.4 Materiais, peças e componentes & & & 16.093 & 16.093 & $2,7 \%$ \\
\hline 1.5 Investimento socioambiental & & 2.749 & & 2.749 & $0,5 \%$ \\
\hline 1.6 Taxas e emolumentos & 6.000 & & & 6.000 & $1,0 \%$ \\
\hline 1.7 Treinamentos em qualidade & & 488 & 488 & 976 & $0,2 \%$ \\
\hline 2 Equipamentos nacionais & & 6.826 & 8.688 & 15.154 & $2,6 \%$ \\
\hline \multirow[t]{2}{*}{3 ltens não financiáveis } & & 11.000 & 14.000 & 25.000 & $4,3 \%$ \\
\hline & 6.000 & 354.624 & 225.376 & 586.000 & $100,0 \%$ \\
\hline $\begin{array}{l}\text { Total das fontes } \\
\text { Projeto Arena Mineirão }\end{array}$ & $\begin{array}{r}\text { Realizado até } \\
2010\end{array}$ & 2011 & 2012 & Total & $\%$ \\
\hline 1 Recursos próprios & 6.000 & 97.491 & 82.509 & 186.000 & $31,7 \%$ \\
\hline \multirow{2}{*}{2 Financiamento BNDES } & & 257.133 & 142.867 & 400.000 & $68,3 \%$ \\
\hline & 6.000 & 354.624 & 225.376 & 586.000 & $100,0 \%$ \\
\hline
\end{tabular}

Fonte: TCU (2012).

Outras informações obtidas na pesquisa documental foram entrevistas e reportagens que destacaram o aspecto sustentável do Estádio do Mineirão. Em reportagem da TV Assembleia, no programa Repórter Assembleia, em 12 de maio de 2014, foi informado que o investimento com a usina solar do estádio, no valor de R 15 milhões, foi custeado pela empresa Cemig (TV Assembleia, 2014). Assim, considera-se que os custos para atingir ganhos de energia não fizeram parte das avaliações apresentadas pelo gerente de tecnologia da Minas Arena.

Por sua vez, em entrevista ao programa "Bom Dia MG", da Rede Globo de Televisão, em 4 de setembro de 2015, o gerente de tecnologia da Minas Arena, Sr. Otávio Goés, afirmou que o investimento total em tecnologia no estádio atingiu o percentual de 15\% (Rede Globo, 2015). Entretanto, nesses valores foram computados todos os custos com equipamentos de tecnologia, incluindo, conforme citado na entrevista, equipamentos de vigilância e segurança (câmeras para circuito fechado de televisão, telões, sistema online de catracas, equipamentos de detecção de incêndios), sendo certo que parte considerável desses custos são inerentes a qualquer tipo de construção.

Ainda de acordo com o entrevistado citado, todos os equipamentos eram monitorados por sistema de automação, o qual se incumbia de ligar, desligar, ajustar a operação de cada um dos elementos monitorados, podendo considerar que esse sistema de automação era responsável por tornar a construção sustentável.

Considerando que o atendimento à construção sustentável e a obtenção de uma certificação reconhecida internacionalmente eram condições básicas para a obtenção de financiamento com o BNDES, é possível assumir como premissa que custos adicionais ao de uma construção sem esses requisitos sequer chegaram a ser calculados. Por outro lado, não é plausível afirmar que o investimento total em construção sustentável seja representado apenas pela rubrica "investimento socioambiental", que representa apenas $0,5 \%$ do total de investimento, conforme Tabela 4.

Mais provável que esses investimentos tenham sido diluídos em todas as rubricas que compõem o custo total do projeto. Entretanto, uma parcela significativa de custo (R\$ 15 milhões) referente à usina solar implementada também não foi computada no valor. Caso esse custo fosse incorporado ao valor total do custo da construção, o montante atingiria a cifra de $\mathrm{R} \$ 662.931 .000,00$, sendo sua participação correspondente a $2,3 \%$ do investimento total. 
Assumindo os percentuais em lados radicalmente opostos, é possível afirmar que os custos com a construção sustentável estariam entre 0,42 e 17,8\% (15\% + 2,8\%). Levando-se em conta que a implantação do sistema de geração de energia solar, bem como os gastos com tecnologia, deva ser incorporada ao custo total da construção, são adotados os seguintes cenários:

- cenário 1: adota-se a estimativa de Kats (2003), ou seja, os custos para obter a certificação Platinum alcançam 6,5\% do investimento. Nesse cenário, o custo da construção sustentável seria de $\mathrm{R} \$ 43.090 .515,00$;

- cenário 2: adota-se a estimativa mais pessimista de Nyikos et al. (2012). Assim, para tornar uma construção sustentável, é necessário considerar 9,4\% do investimento, com o valor considerado para esse cenário de $\mathrm{R} \$ 62.315 .000,00$; e

- cenário 3: admite-se o percentual de 15\% informado pelo gerente de tecnologia da Minas Arena (Rede Globo, 2015). Nesse cenário, o valor do investimento total em tecnologias que auxiliam na sustentabilidade da edificação atinge o montante de $\mathrm{R} \$ 99.439 .650,00$.

Para mensurar o impacto econômico por meio das reduções de custos incorridas, foram utilizadas as informações constantes no website do Estádio do Mineirão (Minas Arena, 2017). De acordo com essa fonte, os ganhos obtidos com a construção do estádio com conceitos de sustentabilidade ambiental compreendem o aproveitamento de luz solar por meio de usina solar fotovoltaica e a reutilização de água da chuva, ou seja, eficiência energética. Além destes, o website do estádio destaca também o reaproveitamento de resíduos, feito em parceria com uma associação de catadores de papel, papelão e materiais reaproveitáveis.

Por essa razão, possíveis ganhos não foram considerados nesse cálculo. Ainda de acordo com as entrevistas e reportagens, pelo projeto idealizado, são realizados reaproveitamentos de calor gerado pelo sistema de ar-condicionado para aquecimentos diversos e redução de consumo de energia elétrica pela utilização inteligente de sistemas de iluminação, que privilegiavam o uso da luz solar. Entretanto, não foi possível apurar, pelas informações disponíveis, o quanto esses fatores beneficiariam em termos econômicos.

A usina solar fotovoltaica é composta de 6 mil células de silício cristalino, cobrindo uma área de 9.500 metros quadrados e sendo capaz de gerar $1.600 \mathrm{MWh} / \mathrm{ano}$ (Minas Arena, 2017). 0 website da concessionária de energia elétrica CEMIG aponta que, para consumidores de 88 a $138 \mathrm{KV}$, o valor do KWh é de $\mathrm{R} \$ 0,44242$ (CEMIG, 2017). Com isso, tem-se que o custo de 1 MWh seria de $R \$ 442,42$, portanto a produção de $1.600 \mathrm{MWh} /$ ano geraria um ganho de $\mathrm{R} \$ 707.872,00$.

No quesito de reaproveitamento de água, o website do Estádio do Mineirão aponta que os tanques de armazenamento de água têm capacidade para acumular 5 milhões de litros de água, capazes de abastecer o estádio por três meses (Minas Arena, 2017). Assim, assumindo que a quantidade de água captada pela chuva no estádio é de 20 milhões de litros ( 5 milhões a cada 0,25 ano) ou 20 mil metros cúbicos, a Companhia de Saneamento de Minas Gerais (SANASA, 2017) indica que as tarifas para consumidores, na categoria comercial com consumo acima de 50 metros cúbicos, são as seguintes:

- Água tratada $\left(\mathrm{R} \$ / \mathrm{m}^{3}\right)=\mathrm{R} \$ 28,73$ com parcela a deduzir de $\mathrm{R} \$ 644,89$

- Coleta de esgoto $\left(\mathrm{R} \$ / \mathrm{m}^{3}\right)=\mathrm{R} \$ 22,99$ com parcela a deduzir de $\mathrm{R} \$ 516,30$

- Tratamento de esgoto $\left(\mathrm{R} \$ / \mathrm{m}^{3}\right)=\mathrm{R} \$ 12,35$ com parcela a deduzir de $\mathrm{R} \$ 276,75$

Aplicando-se as tarifas, o ganho com a reutilização da água chegaria a $\mathrm{R} \$ 1.279 .962,06$ ao ano, que, somado ao ganho com a energia elétrica citado de $\mathrm{R} \$ 707.872,00$, daria uma redução no custo total de $\mathrm{R} \$ 1.987 .834,06$, que seria o benefício anual no fluxo de caixa, considerando que ele esteja a valor presente. Esse valor deveria ser atualizado monetariamente, já que está sendo apurado o ganho em $\mathrm{MWh}$ de energia elétrica ou metro cúbico $\left(\mathrm{m}^{3}\right)$ de água. A Tabela 5 evidencia os ganhos ou as perdas com a construção sustentável nos cenários mencionados. 
Tabela 5 - Cenários de avaliação de custos em construção sustentável

\begin{tabular}{cccccc}
\hline Cenário & $\begin{array}{c}\text { Investimento inicial } \\
\left(\mathrm{I}_{0}\right)\end{array}$ & $\begin{array}{c}\text { Benefício } \\
\text { anual }\left(\mathrm{T}_{0}\right)\end{array}$ & $\begin{array}{c}\text { Redução de custos } \\
\text { total }\end{array}$ & $\begin{array}{c}\text { Ganho / } \\
\text { perda (\$) }\end{array}$ & $\begin{array}{c}\text { Ganho/perda } \\
(\%)\end{array}$ \\
\hline 1 & $\mathrm{R} \$ 43.090 .515,00$ & $\mathrm{R} \$ 1.987 .834,06$ & $\mathrm{R} \$ 49.695 .851,50$ & $\mathrm{R} \$ 6.605 .336,50$ & $15,3 \%$ \\
2 & $\mathrm{R} \$ 62.315 .000,00$ & $\mathrm{R} \$ 1.987 .834,06$ & $\mathrm{R} \$ 49.695 .851,50$ & $\mathrm{R} \$ 12.619 .148,50$ & $-20,3 \%$ \\
3 & $\mathrm{R} \$ 99.439 .650,00$ & $\mathrm{R} \$ 1.987 .834,06$ & $\mathrm{R} \$ 49.695 .851,50$ & $\mathrm{R} \$ 49.743 .798,50$ & $-50,0 \%$ \\
\hline
\end{tabular}

Fonte: elaborada pelos autores.

Considerando que o benefício anual é de $\mathrm{R} \$ 1.987 .834,06$ (a valor presente), a redução de custos no total dos 25 anos seria de $\mathrm{R} \$ 49.695 .851,50$ (a valor presente). Dessa maneira, apenas no cenário 1 é que a redução de custos total (os ganhos de energia e de reaproveitamento de água da chuva) compensaria o valor do investimento na construção sustentável em $\mathrm{R} \$ 6.605 .336,50$, ou $15,3 \%$ do valor do investimento inicial de $\mathrm{R} \$ 43.090 .515,00$.

Nos cenários 2 e 3, evidencia-se que os ganhos obtidos são menores que os investimentos realizados na construção sustentável, o que não justificaria os custos adicionais para sua implantação, isso analisando apenas os impactos econômicos. No cenário 2, há uma perda de 20,3\%, enquanto no cenário 3 a perda estimada é de $50 \%$.

Outros aspectos de redução de custos não puderam ser verificados apenas pela pesquisa documental, tais como: ganhos de energia elétrica com os sistemas de ar-condicionado, iluminação, sensores de presença, utilização de lâmpadas eficientes, ventilação natural, entre outros, que são avaliados no projeto para a certificação LEED. No caso dos estádios da Copa do Mundo de 2014, a fim de obter recursos do BNDES, todos os projetos buscaram a certificação, portanto já partiram considerando esses critérios.

\section{Conclusões}

Se, no passado, as questões sobre construção civil concentravam-se majoritariamente nas técnicas de arquitetura e urbanismo e engenharia civil, hoje os aspectos sustentáveis assumiram papel de destaque, uma vez que podem postergar ou mesmo impedir a evolução de empreendimentos que não considerem os pilares ambientais, sociais e econômicos em seus requisitos. Nesse cenário, as construções sustentáveis passaram a ter uma dimensão muito maior, e, para que se evite o "esverdeamento" apenas midiático, certificações são apresentadas para diferenciar empreendimentos que, de fato, preocupam-se com os conceitos da sustentabilidade.

Um aspecto importante a salientar é que a consciência da sustentabilidade se fez presente nos projetos das obras da Copa do Mundo de 2014, pois, praticamente, não havia a possibilidade de deixar de pensar em soluções sustentáveis nos projetos por causa da impossibilidade de obtenção de recursos no BNDES. 0 resultado das certificações (Tabela 3 ) demonstra que $2 / 3$ das arenas e dos estádios lograram êxito na obtenção das certificações, o que indica que, nesses casos, o aspecto sustentável foi verificado.

A obtenção do nível mais elevado da certificação internacional LEED no estádio do Mineirão demonstrou que os esforços não se deram apenas para cumprir com a obrigação imposta pelo BNDES, mas reforça que, quando se considera o empreendimento no longo prazo, busca-se retornos econômicos, tal como defendido por Azhar et al. (2011), Kats (2003), Kats et al. (2003), Nyikos et al. (2012), von Paumgartten (2003) e Vimpari \& Junnila (2014).

No que tange ao objetivo deste trabalho de mensurar o impacto econômico da adoção do conceito de construção sustentável no projeto do Estádio do Mineirão (MG), pode-se dizer que, com base nas informações disponíveis, os custos iniciais com a construção sustentável estão entre $0,5 \%$ do total do investimento (conforme TCU), mais $2,3 \%$ da usina fotovoltaica instalada e $15 \%$ do investimento em tecnologia, ou seja, $17,8 \%$ do total do investimento.

Em relação à redução de custos anuais, pode-se dizer que é estimada uma redução de $\mathrm{R} \$ 1.987 .834,06$, proveniente de eficiência energética. Isso está em consonância com a opinião de Goldemberg \& Lucon 
(2007, p. 18), de que "[...] a eficiência energética é, sem dúvida, a maneira mais efetiva de ao mesmo tempo reduzir os custos e os impactos ambientais locais e globais [...]". Essa questão vem ao encontro do que foi discutido por Gavronski (2009) e Bonilla et al. (2012).

Como sugestão para estudos futuros, pode-se pensar em mensurar os custos de outras construções sustentáveis de estádios ou outras obras relevantes no país, com dados reais e fornecidos pelas empresas pesquisadas, bem como comparar os custos de manutenção mensal ou anual de estádios e arenas certificados, recém-construídos ou adaptados, além daqueles que ainda não tenham passado por esse processo.

Este trabalho apresenta como limitação o fato de ter considerado apenas dados secundários obtidos por meio de pesquisa documental. Os aspectos econômicos da realização da Copa do Mundo no Brasil ainda suscitam discussões sobre a relevância ou não dos investimentos realizados. As mensurações aqui realizadas foram desenvolvidas apenas com base na pesquisa documental.

Como contribuição para a área das ciências sociais aplicadas, em especial para a administração, considera-se que foi mensurado o impacto econômico de uma construção sustentável, por meio de redução de custos, que é um assunto pouco abordado na literatura, tanto no que diz respeito ao percentual de investimento em sustentabilidade no total do investimento de um empreendimento quanto na redução dos custos anuais, por meio de eficiência energética, evidenciando a relevância desse assunto.

Em que pesem a dificuldade na obtenção e a transparência de dados econômico-financeiros por parte de organizações privadas ou públicas, ressalta-se que iniciativas de vinculação de contrapartida sustentável a investimentos públicos tornam-se uma espécie de ação afirmativa na busca por soluções para um mundo sustentável.

\section{Referências}

Azhar, S., Carlton, W. A., Olsen, D., \& Ahmad, I. (2011). Building information modeling for sustainable design and LEED ${ }^{\circledR}$ rating analysis. Automation in Construction, 20(2), 217-224.

http://dx.doi.org/10.1016/j.autcon.2010.09.019.

Banco Nacional de Desenvolvimento Econômico e Social - BNDES. (2014). Programa BNDES de Arenas para a Copa do Mundo de 2014 - BNDES ProCopa Arenas. Recuperado em 12 de fevereiro de 2017, de http://www.bndes.gov.br/wps/portal/site/home/patrocinios/patrocinio-ao-esporte/bndes-procopa-arenas

Barbieri, J. C. (1995). Avaliação de impacto ambiental na legislação brasileira. Revista de Administração de Empresas, 35(2), 78-85. http://dx.doi.org/10.1590/S0034-75901995000200010.

Bonilla, S. H., Almeida, C. M. V. B., Giannetti, B. F., \& Huisingh, D. (2012). Key elements, stages and tools for a sustainable world: an introduction to this special volume. Journal of Cleaner Production, 46, 1-7. https://doi.org/10.1016/j.jclepro.2012.12.011.

Brasil. Conselho Monetário Nacional - CMN. Banco Central do Brasil. (2009). Resolução 3.801. Acrescenta o art. $9^{\circ}$ - $Q$ à Resolução no 2.827, de 30 de março de 2001, com vista a estabelecer linha de financiamento do Banco Nacional de Desenvolvimento Econômico e Social (BNDES) para contratação de operações de crédito para construção e reforma de estádios da Copa 2014. Brasília: Diário Oficial da União. Recuperado em 25 de fevereiro de 2017, de https://www.bcb.gov.br/pre/normativos/busca/normativo.asp?tipo=res\&ano=2009\&numero=3801

Brasil. (2014). Palco de semifinal - Mineirão é primeiro estádio do Brasil a receber selo máximo de sustentabilidade. Recuperado em 12 de fevereiro de 2017, de http://www.brasil.gov.br/centro-aberto-de-midia/noticias/palco-desemifinal-mineirao-e-primeiro-estadio-do-brasil-a-receber-selo-maximo-de-sustentabilidade

Bueno, C., \& Rossignolo, J. A. (2010). Desempenho ambiental de edificações: cenário atual e perspectivas dos sistemas de certificação. Minerva, 7(1), 45-52.

Candace Say. (2008). Sustainable rating systems around the world. Council on Tall Buildings and Urban Habitat Journal, (2), 18-29. 
Companhia Energética de Minas Gerais S.A. - CEMIG. (2017). Valores de tarifas e serviços. Recuperado em 25 de fevereiro de 2017, de http://www.cemig.com.br/pt-br/atendimento/Paginas/valores_de_tarifa_e_servicos.aspx

Construindo um Brasil Sustentável - GBC Brasil. (2017). Construindo um futuro sustentável. Recuperado em 20 de setembro de 2017, de http://www.gbcbrasil.org.br/empreendimentos-leed.php

Dalla Costa, E., \& Moraes, C. S. B. (2013). Construção Civil e a certificação ambiental: análise comparativa das certificações LEED (Leadership in Energy and Environmental Design) e AQUA (Alta Qualidade Ambiental). Engenharia Ambiental, 10(3), 160-169.

Gareis, R. (2013). Re-thinking project initiation and project management by considering principles of sustainable development. In: G. Silvius, \& J. Tharp (Eds.), Sustainability integration for effective project management. Hershey: Business Science Reference. http://dx.doi.org/10.4018/978-1-4666-4177-8.ch008.

Gareis, R., Huemann, M., \& Martinuzzi, A. (2013). Project management and sustainable development principles. Newtown Square: Project Management Institute.

Gavronski, I. (2009). Estratégia de operações sustentáveis: produção, suprimentos, logística e engenharia alinhados com a sustentabilidade corporativa (Tese de doutorado). Programa de Pós-graduação em Administração, Universidade Federal do Rio Grande do Sul, Porto Alegre.

Gil, A. C. (2010). Como elaborar um projeto de pesquisa (5. ed.). São Paulo: Atlas.

Goldemberg, J., \& Lucon, O. (2007). Energia e meio ambiente no Brasil. Estudos Avançados, 21(59), 7-20. http://dx.doi.org/10.1590/S0103-40142007000100003.

Kats, G. H. (2003). Green building costs and financial benefits. Recuperado em 20 de fevereiro de 2017, de http://www.greenspacebuildings.com/wp-content/uploads/2011/05/Kats-Green-Buildings-Cost.pdf

Kats, G. H., Alevantis, L., Berman, A., Mills, E., \& Perlman, J. (2003). The costs and financial benefits of green buildings a report to California's sustainable building task force. Recuperado em 25 de janeiro de 2017, de http://www.usgbc.org/resources/costs-and-financial-benefits-green-buildings-report-california?s-sustainablebuilding-task

Lützkendorf, T., \& Lorenz, D. (2005). Sustainable Property Investment: vlauing sustainable buildings through property performance assessment. Building Research and Information, 33(3), 212-234.

http://dx.doi.org/10.1080/09613210500070359.

Malheiros, T. F., Coutinho, S. M. V., \& Philippi, A., Jr. (2013). Desafios do uso de indicadores na avaliação da sustentabilidade. In T. F. Malheiros \& Philippi, A., Jr. (Eds.), Indicadores de sustentabilidade e gestão ambiental. Barueri: Manole.

Martins, V. W. B., Neves, R. M., \& Macêdo, A. N. (2014). Análise do desenvolvimento de competências gerenciais na Construção Civil através do modelo da Aprendizagem Baseada em Problemas adaptado ao contexto organizacional. Ambiente Construído, 14(1), 155-175. http://dx.doi.org/10.1590/S1678-86212014000100013.

Medeiros, M. L., Machado, D. F. C., Passador, J. L., \& Passador, C. S. (2012). Adoção da certificação LEED em meios de hospedagem: esverdeando a hotelaria? RAE - Revista de Administração de Empresas, 52(2), 179-192.

Minas Arena. (2017). Estadio Mineirão. Recuperado em 28 de fevereiro de 2017, de http://estadiomineirao.com.br/o-mineirao/Sustentabilidade/

Minas Gerais. Programa de Parceria Público-Privada do Estado de Minas Gerais. (2010a). Edital PPP Mineirão. Recuperado em 13 de fevereiro de 2017, de http://ppp.mg.gov.br/images/documentos/Projetos/concluidos/Mineirao/Edital PPP Mineirao.pdf

Minas Gerais. Programa de Parceria Público-Privada do Estado de Minas Gerais. (2010b). Contrato de concessão administrativa. Recuperado em 12 de fevereiro de 2017, de http://ppp.mg.gov.br/images/documentos/Projetos/concluidos/Mineirao/Contrato_PPP_Mineirão_Final_assinad o.pdf 
Minas Gerais. Programa de Parceria Público-Privada do Estado de Minas Gerais. (2012). Fatos e dados de projetos. Recuperado em 13 de fevereiro de 2017, de http://ppp.mg.gov.br/images/Minerao/Prospecto_PPP_Novo_Mineirão.pdf

Nidumolu, R., Prahalad, C. K., \& Rangaswami, M. R. (2009). Why sustainability is now the key driver of innovation. Harvard Business Review, (Sept), 1-10.

Nunes, T. C. S., Nova, S. C., Cornacchione, E., \& Garcia, S. (2012). Are sustainable companies less risky and more profitable? Revista de Administração - RAUSP, 47(2002), 422-435.

Nyikos, D. M., Thal, A. E., Jr., Hicks, M. J., \& Leach, S. E. (2012). To LEED or not to LEED: analysis of cost premiums associated with sustainable facility design. Engineering Management Journal-Rolla, 24(4), 50-62. http://dx.doi.org/10.1080/10429247.2012.11431955.

Rede Globo. (2015). Bom dia MG edição 04/09/2015. Recuperado em 12 de janeiro de 2017, de http://g1.globo.com/minas-gerais/videos/t/todos-os-videos/v/reforma-feita-no-mineirao-para-a-copa-domundo-deixou-o-estadio-mais-moderno/4443127/

Silva, V. G., \& Pardini, A. F. (2010). Contribuição ao entendimento da aplicação da certificaçao LEED no Brasil com base em dois estudos de caso. Ambiente Construído, 10(3), 81-97. http://dx.doi.org/10.1590/S167886212010000300006.

Silva, V. G., Silva, M. G., \& Agopyan, V. (2003). Avaliação de edifícios no Brasil: da avaliação ambiental para avaliação de Sustentabilidade. Ambiente Construído, 3(3), 7-18.

Sociedade de Abastecimento de Água e Saneamento S/A - SANASA. (2017). Tarifas de saneamento. Recuperado em 25 de fevereiro de 2017, de http://www.sanasa.com.br/document/noticias/2291.pdf

Souza, M. T. S., \& Ribeiro, H. C. M. (2013). Sustentabilidade ambiental: uma meta-análise da produção brasileira em periódicos de administração. RAC. Revista de Administração Contemporânea, 17(3), 368-396. http://dx.doi.org/10.1590/S1415-65552013000300007.

Tribunal de Contas da União - TCU. (2012). Relatório TC 015.236/2011-0. Recuperado em 25 de janeiro de 2017, de https://contas.tcu.gov.br/sagas/SvlVisualizarRelVotoAcRtf\%3FcodFiltro\%3DSAGAS-SESSAOENCERRADA\%26seOcultaPagina\%3DS\%26item0\%3D436223+\&cd=2\&hl=pt-BR\&ct=clnk\&gl=b

Tribunal de Contas da União - TCU. (2014). Relatório TC 028.249/2013-5. Recuperado em 25 de janeiro de 2017, de https://contas.tcu.gov.br/sagas/SvlVisualizarRelVotoAcRtf\%3FcodFiltro\%3DSAGAS-SESSAOENCERRADA\%26seOcultaPagina\%3DS\%26item0\%3D494681+\&cd=1\&hl=pt-BR\&ct=clnk\&gl=br

TV Assembleia. (2014). Mineirão sustentável - repórter assembleia. Recuperado em 25 de janeiro de 2017, de www.youtube.com/watch?v=AePmYnGbEvQ

USGreen Building Council - USGBC. (2013). LEED reference guide for building design and construction, LEED V4. Recuperado em 23 de janeiro de 2017, http://www.usgbc.org/resources/leed-v4-building-design-andconstruction-current-version

Van Bellen, H. M. (2004). Indicadores de sustentabilidade: um levantamento dos principais sistemas de avaliação. Cadernos EBAPE.BR, 2(1), 1-14.

Vimpari, J., \& Junnila, S. (2014). Valuing green building certificates as real options. Journal of European Real Estate, 7(2), 181-198. http://dx.doi.org/10.1108/JERER-06-2013-0012.

von Paumgartten, P. (2003). The business case for high performance green buildings: sustainability and its financial impact. Journal of Facilities Management, 2(1), 26-34. http://dx.doi.org/10.1108/14725960410808096.

Walker, K., \& Wan, F. (2012). The harm of symbolic actions and green-washing: corporate actions and communications on environmental performance and their financial implications. Journal of Business Ethics, 109(2), 227-242. http://dx.doi.org/10.1007/s10551-011-1122-4. 
Zangalli, P. C., Jr. (2013). Sustentabilidade urbana e as certificações ambientais na Construção Civil / Urban Sustainability and Environmental Certifications in Construction. Revista Sociedade \& Natureza, 25(2), 291-302. http://dx.doi.org/10.1590/S1982-45132013000200007.

Editor: Harry Bollmann

Recebido: Fev. 11, 2018

Aprovado: Jun. 06, 2018 